\title{
Gabapentin reverses central pain sensitization following a collagenase-induced intrathalamic hemorrhage in rats
}

This article was published in the following Dove Press journal: Journal of Pain Research

16 December 2013

Number of times this article has been viewed

\section{Aude Castel \\ Pascal Vachon}

Faculty of Veterinary Medicine, Department of Veterinary Biomedicine, University of Montreal, Saint-Hyacinthe, QC, Canada
Correspondence: Pascal Vachon Université de Montréal, Faculté de Médecine Vétérinaire, Département de Biomédecine Vétérinaire, 3200 Sicotte, St-Hyacinthe, QC H2L 2M2, Canada Tel + I 450773852 I ext 8294 Email pascal.vachon@umontreal.ca
Purpose: The treatment of central neuropathic pain remains amongst the biggest challenges for pain specialists. The main objective of this study was to assess gabapentin (GBP), amitriptyline (AMI), and carbamazepine (CARBA) for the treatment of a rodent central neuropathic pain model.

Methods: Male Sprague Dawley rats were trained on the rotarod, Hargreaves, Von Frey and acetone behavioral tests, and baseline values were obtained prior to surgery. A stereotaxic injection of either a collagenase solution or saline was made in the right ventral posterolateral thalamic nucleus. The rats were tested on days $2,4,8$, and 11 postsurgery. They were retested at regular intervals from day 15 to day 25 postsurgery, after oral administration of either the vehicle $(n=7$ and $n=8$ rats with intracerebral injections of collagenase and saline, respectively) or the different drugs (GBP [60 mg/kg], AMI [10 mg/kg], CARBA [100 mg/kg]; n=8 rats/drug).

Results: A significant decrease in the mechanical thresholds and no change in heat threshold were observed in both hind limbs in the collagenase group, as we had previously shown elsewhere. Reversal of the mechanical hypersensitivity was achieved only with GBP $(P<0.05)$. AMI and CARBA, at the dosages used, failed to show any effect on mechanical thresholds. Transient cold allodynia was observed in some collagenase-injected rats but failed to be statistically significant.

Conclusion: Intrathalamic hemorrhaging in the ventrolateral thalamic nucleus induced a bilateral mechanical allodynia, which was reversed by GBP but not AMI or CARBA.

Keywords: central pain, thalamus, amitriptyline, carbamazepine

\section{Introduction}

Anticonvulsants and antidepressants are commonly used for the treatment of chronic neuropathic pain. ${ }^{1}$ Among the various types of chronic neuropathic pain, central poststroke pain (CPSP) is a condition caused by a vascular lesion in the central nervous system, involving the spinothalamocortical pathway responsible for the transmission of thermal and pain sensation. ${ }^{2}$ According to population-based studies, the incidence of CPSP varies around $10 \%$ but may be higher following thalamic lesions, particularly if right sided..$^{3-6}$ The ventroposterior nuclei of the thalamus are reported to play a key role in central pain. ${ }^{7,8}$

CPSP is characterized by sensory deficits, such as allodynia to thermal or mechanical stimuli, dysesthesia, and hyperalgesia., ${ }^{5,9}$ The pain can be spontaneous or evoked by stimuli, such as thermal stimuli (especially cold); mechanical stimuli, such as touch or movement, or even by stress. ${ }^{10,11}$ The development of pain in stroke patients is of great concern since it lessens their quality of life by interfering with daily activities, 
mood, walking ability, normal work, social interaction, sleep, and enjoyment of life, eventually leading to depression. ${ }^{12,13}$ Therefore, the diagnosis and management of CPSP represents a major concern and a real medical challenge.

In terms of treatment recommendations, the use of tricyclic antidepressants, such as amitriptyline (AMI), and anticonvulsants, such as carbamazepine (CARBA) or gabapentin (GBP), are often the first steps of the therapeutic plan to treat CPSP. ${ }^{14}$ AMI has been used for the treatment of diabetic neuropathy, cancer neuropathic pain, and thalamic pain. ${ }^{15-17}$ GBP was first used for the treatment of epilepsy; ${ }^{18}$ however, more recently, it has shown to be effective in the treatment of neuropathic pain of either peripheral or central origin. ${ }^{18,19}$ CARBA has inhibitory effects on spontaneous spinal neural activity as well as on noxious and nonnoxious evoked responses, in a spinal nerve ligation model. ${ }^{20}$ Spontaneous activity, characterized by low-threshold calcium burst spikes within the thalamus, has been reported in patients with central pain. ${ }^{21,22}$ Thus, there is a rationale that CARBA might also decrease central pain in a rodent model. AMI, CARBA, and GBP are therefore, proposed therapeutic strategies for the treatment of central thalamic pain.

Until recently, the lack of a reliable animal model has prevented a true understanding of the underlying mechanisms of CPSP. In 2009, Wasserman and Koeberle ${ }^{23}$ produced a model of this condition by injecting a collagenase solution within the ventroposterolateral (VPL) thalamic nucleus of rats. The collagenase acts by disrupting the blood vessels, thus inducing a well-localized hemorrhage, with the extent of the lesion depending on the amount of collagenase injected. ${ }^{24}$ In a recent study from our lab, a collagenase injection within the right VPL thalamic nucleus of rats produced persistent bilateral mechanical allodynia, which developed from the second day after the injection, and transient cold allodynia. ${ }^{25}$ Animal models can help to further understand the mechanisms involved in CPSP and allow experimentation with different therapeutic approaches for this condition. The main objective of the present study was to evaluate the effects of AMI, GBP, and CARBA on central neuropathic pain, using a rodent model of intrathalamic collagenase-induced hemorrhage.

\section{Materials and methods}

\section{Animals}

Forty Sprague Dawley ${ }^{\circledR}$ rats (Charles River, Wilmington, MA, USA), between 7 and 8 weeks of age (body weight: 300-350 g), were used for this study. They were housed in a standard research environment (temperature: $21^{\circ} \mathrm{C} \pm 3{ }^{\circ} \mathrm{C}$; fresh filtered air [15 changes/h]; humidity 40\%-60\%; light-dark cycle [12 hours:12 hours]). The rats were pairhoused in polycarbonate cages (Ancare Corp, Bellmore, NY, USA) with hardwood bedding (Beta Chip ${ }^{\circledR}$, Northeastern Products Corp, Warrensburg, NY, USA) and acclimated for 7 days prior to the study. The animals were fed a rodent chow (Rodent Chow 5075; Charles River) and received tap water, both, ad libitum. The Animal Care and Use Committee of the University of Montreal Faculty of Veterinary Medicine approved the protocol prior to animal use. All procedures were conducted in accordance with the guidelines of the Canadian Council on Animal Care.

\section{Surgical techniques}

The rats were divided in two groups $(n=8$ in the sham [SHAM] group; $n=32$ in the collagenase group). The surgical details have previously been described by Wasserman and Koeberle. ${ }^{23}$ The animals were anesthetized using vaporized isoflurane (3\%) (AErrane; Baxter Healthcare Corp, Deerfield, IL, USA) in oxygen. A regulated heating blanket was used to keep the temperature within normal limits $\left(36^{\circ} \mathrm{C}-37^{\circ} \mathrm{C}\right)$. Body temperature was monitored using a rectal probe (TH-8 Thermalert Monitoring Thermometer; Physitemp, Clifton, NJ, USA). The skin hair of the skull was clipped and cleaned with a Proviodine ${ }^{\circledR}$ solution. A sagittal skin incision was made from the frontal to the occipital bone, and the periosteum was gently detached. The area of interest $(3.5 \mathrm{~mm}$ anterior and posterior, and $3.5 \mathrm{~mm}$ lateral to the bregma $)^{26}$ was localized using a stereotaxic apparatus (Small Animal Stereotaxic Instrument; David Kopf Instruments, Tujunga, CA, USA). A $1.5 \mathrm{~mm}$ burr hole (diameter $1.5 \mathrm{~mm}$ ) was made using a stereotaxic drill, (Foredorn flex shaft drill, Stoelting Co., Wood Dale, IL, USA) and injections were done using a Hamilton syringe (Hamilton Company, Reno, NV, USA). The collagenase group received $0.25 \mu \mathrm{L}$ of a solution of $0.025 \mathrm{UI}$ of collagenase Type IV (Sigma-Aldrich Corp, St Louis, MO, USA) in sterile saline. The syringe was lowered ( $6 \mathrm{~mm}$ ventral) so that the injection site would be within the right ventral posterolateral thalamic nucleus. Similar surgical and injection procedures were performed in "SHAM" animals receiving an equal volume of sterile saline $(0.9 \% \mathrm{NaCl})$. The total injection time was 2 minutes, and the needle was left in place another 5 minutes to prevent any reflux. Following the injection, the skin was closed using simple discontinuous Monocryl 4.0 sutures (Ethicon Inc., Cincinnati, OH, USA). The animals were caged singly for the duration of the study. 
One animal died of isoflurane overdose during surgery, leaving 31 animals in the collagenase group.

\section{Behavioral study}

The animals were trained daily for 1 week prior to the beginning of the behavioral evaluation, in the following sequential order: rotarod treadmill, Von Frey filaments, acetone and Hargreaves tests. Baseline values were obtained 3 days prior to surgery. After surgery, the animals were given 1 day to recover and were then tested on days $2,4,8$, and 11 postsurgery to evaluate their temperature and mechanical threshold as well as motor coordination. They were tested again on day $15,18,22$, and 25 following the treatment administration. The tests were always performed in the morning ( $8-11 \mathrm{am})$, to avoid circadian variations. All the rats were acclimated to the room for 15 minutes and then in each apparatus for 15 minutes prior to testing (except in the case of the rotarod evaluation).

\section{Rotarod test}

Motor coordination was evaluated with the rotarod treadmill (Standard Rota-Rod for Rat ENV-576; Med Associates Inc., St Albans, VT, USA). The acceleration was set from 5 to 35 rpm over 5 minutes. The maximal time the animal was able to stay on the rotarod (up to a maximum of 5 minutes) without falling was recorded for each performance.

\section{Von Frey mechanical sensitivity test}

The mechanical threshold was evaluated with Von Frey filaments (Stoelting Co, Wood Dale, IL, USA) using the up-down paradigm. ${ }^{27}$ The rats were placed in Plexiglas ${ }^{\circledR}$ chambers (Plantar Analgesic meter, IITC Life Science Inc., Woodland Hills, CA, USA) set on a customized platform made of wire mesh. The Von Frey filaments, ranging from 4 to $22 \mathrm{~g}$, were applied, for up to 3 seconds, to the plantar surface of the rats' hind paws. To avoid the effect of anticipation, a first paw was tested in all animals, and then, the opposite paw and sequence of testing (right or left paws) was alternated at each testing sequence. The force of the smallest filament causing a withdrawal reaction was recorded as the threshold. A force calibration was performed for each filament at the beginning and at the end of the study.

\section{Acetone test}

The cold threshold was evaluated according to the method previously described by Choi et al. ${ }^{28}$ Briefly, a drop of acetone $(25 \mu \mathrm{L})$ (laboratory grade) was applied with a syringe to the plantar surface of the hind paw. The number of movements of the hind leg and total duration of withdrawal behavior were recorded for 30 seconds. The responses to acetone were graded on the following scale: $0=$ no reaction $1=$ mild reaction, characterized by a quick withdrawal (fewer than three movements) or short duration of lifting paw (fewer than 3 seconds), $2=$ longer withdrawal or repeated movements (three or more movements or $\geq 3$ seconds). To determine the percentage of animals that were reactive to acetone, only grade 2 were considered. The data were presented as the percentage of animals reacting to acetone, per group.

\section{Hargreaves thermal sensitivity test}

Thermal thresholds were evaluated with a Hargreaves apparatus (Plantar Analgesia Meter; IITC Life Science Inc.) as previously described. ${ }^{29}$ Each animal was placed in a Plexiglas chamber with a glass floor heated between $28^{\circ} \mathrm{C}-31^{\circ} \mathrm{C}$. The radiant heat from a high-intensity light bulb $(40 \mathrm{~W})$ was directed to the plantar surface of the hind paw. The withdrawal reaction time was recorded. To avoid the effect of anticipation, a first paw was tested in all animals, and then, the opposite paw and sequence of testing (right or left paws) was alternated at each testing sequence. A cutoff time of 20 seconds was preset to minimize tissue injury.

\section{Treatments}

The animals were fasted the night prior to gavage to avoid a food effect. They were given access to food pellets approximately 15 minutes following the gavage. The operator was blinded to the treatments (type of drug administered). The drugs and methylcellulose were purchased from SigmaAldrich Corp (St. Louis, MO, USA).

The rats from the collagenase group were further divided into four subgroups depending on the treatment received from days 15 to 25 postsurgery. These animals received either a daily oral administration of the vehicle (the control group [CTL]) $(n=7)$ or one of the different drugs (AMI, GBP, or CARBA) ( $\mathrm{n}=8 / \mathrm{drug}$ ). The SHAM group received the vehicle daily by gavage, from days 15 to 25 postsurgery.

The dose concentrations for the three different drugs were chosen according to previous studies showing efficacy in the reduction of neuropathic pain in rodent models. ${ }^{30,31}$ The following doses were administered: AMI $10 \mathrm{mg} / \mathrm{kg}$ (in an emulsion consisting of $0.5 \mathrm{~g} / 100 \mathrm{~mL}$ of the vehicle, for a concentration of $5 \mathrm{mg} / \mathrm{mL}$ ); GBP $60 \mathrm{mg} / \mathrm{kg}$ ( $3 \mathrm{~g}$ GBP in $100 \mathrm{~mL}$ of the vehicle, for a concentration of $30 \mathrm{mg} / \mathrm{mL}$ ); 
and CARBA $100 \mathrm{mg} / \mathrm{kg}$ (in an emulsion of $5 \mathrm{~g}$ dissolved in $100 \mathrm{~mL}$ of vehicle, for a concentration of $50 \mathrm{mg} / \mathrm{mL}$ ). For the SHAM and CTL groups, $0.5 \mathrm{~mL}$ of the solution (composition: $5 \%$ weight $/$ volume $[\mathrm{w} / \mathrm{v}]$ sucrose and $1.5 \%[\mathrm{w} / \mathrm{v}]$ methylcellulose in water) was given orally. The behavioral tests started approximately 1 hour after the gavage.

\section{Histological methods}

Histology was mainly performed to confirm the location of the hemorrhagic lesion. The methods of animal perfusion, tissue collection, and histological staining have previously been described. ${ }^{25}$

\section{Statistical analyses}

An analysis of variance (ANOVA) linear model with repeated measures and post hoc Tukey's tests performed with SAS (version 9.3, SAS Institute Inc., Cary, NC, USA) were used to analyze the data. A priori contrasts with Bonferroni sequential adjustment for multiple comparisons were performed. Comparisons were made between the baseline and the postsurgery and posttreatment values. The SHAM group was also compared with the treatment groups. The results were presented as a mean and standard error (SE). $P$-values $<0.05$ were considered significant. Cochran-Mantel-Haenszel tests were used for the evaluation of cold allodynia.

\section{Results}

\section{Motor coordination evaluated with the rotarod test}

There was no significant difference in motor coordination between the treatment groups (F4, 31=3.29) (nonsignificant $[n s]$ ). For each group, there was no significant difference when comparing the baseline values and all post surgical evaluations, suggesting that neither the CTLs nor the different treatments had an effect on motor coordination (Figure 1).

\section{Mechanical sensitivity evaluated with Von Frey filaments}

A significant effect of treatment occurred for mechanical sensitivity (right hind limb: F 3, 28.1=8.33 $[P=0.0004]$; left: F3, 28.1 $=22.68[P<0.0001]$ ) (Figure 2). Prior to the surgery, the baseline values were not significantly different between the groups, for both hind limbs. For the SHAM group, no difference was seen between the baseline values and postsurgical results. Following surgery, from days 2 to 11 , a significant decrease in the mechanical threshold was noted in the contralateral and ipsilateral hind limbs in the CTL

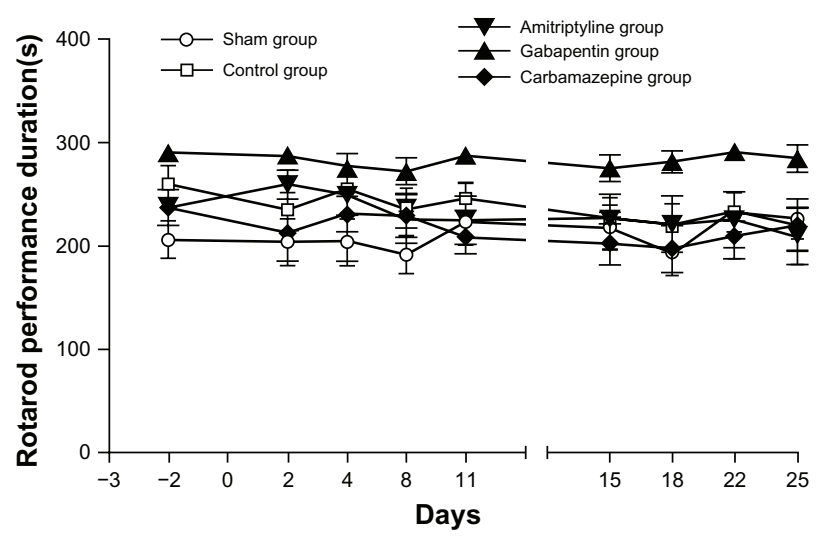

Figure I Results from the rotarod test (motor coordination) evaluated in Sprague Dawley ${ }^{\circledR}$ rats.

Notes: Different groups (sham, control, amitriptyline, gabapentin, and carbamazepine) showed no differences ( $F 4,3 \mathrm{I}=3.29)$ (nonsignificant). No significant difference was seen between all groups at baseline and at different postsurgical time points (F8, I48=1.92) (nonsignificant).

group $(P<0.05)$ compared with that in the SHAM group. This persisted in the CTL group even after treatment with the vehicle. Following treatment, AMI and CARB were showed no effect on mechanical sensitivity. Conversely, GBP reduced mechanical sensitivity, values increasing progressively near SHAM results starting from day 15 onwards.

\section{Evaluation of cold allodynia with the acetone test}

The acetone test results are shown in Figure 3. In the SHAM group, the animals never had significant reactions to acetone following surgery that were different from baseline. Conversely, an increase (graded 2) in the number (three or more movements) and duration of movements ( $\geq 3$ seconds) occurred with acetone, in the animals in the collagenase group. In this group, 10\%-30\% of the animals reacted to acetone between days 2-22 following the surgery. Some animals showed severe allodynia, with duration of movement being around 20 seconds or number of movements being higher than 20 , affecting mainly the left hind limb. However the results were not statistically significant because sensitivity to cold only affected a small number of animals. GBP seemed to reverse the cold allodynia on days 18 and 22 as none of the animals reacted to acetone compared with the other treatments.

\section{Heat sensitivity evaluated with the Hargreaves test}

There was no significant difference in heat sensitivity for both hind limbs (right: F3, 28.2=1.36 [ns]; left: F3, 28.1=1.54 $[\mathrm{ns}]$ ). No significant difference in the thermal threshold was observed when comparing the baseline and any of the postsurgical evaluations for the contralateral and ipsilateral hind limbs in all the groups (Figure 4). 

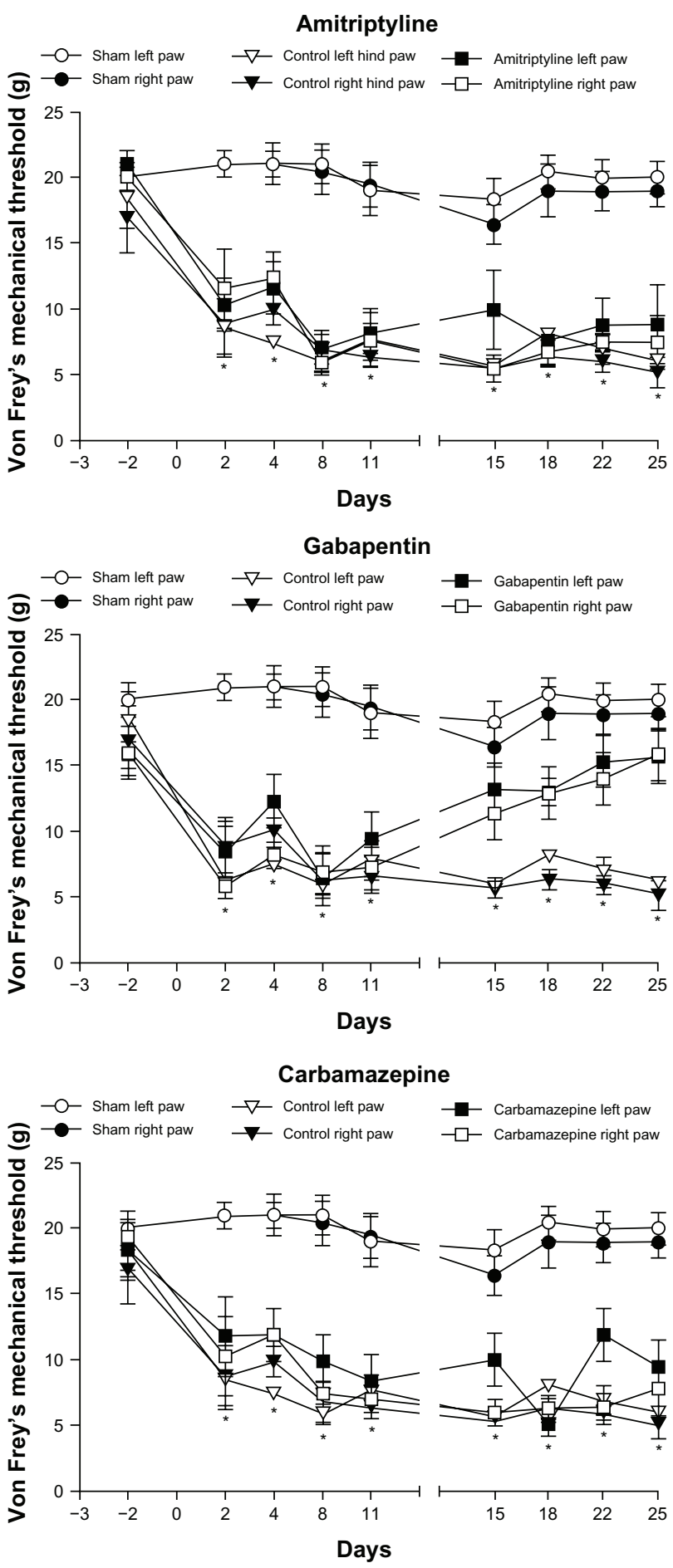

Figure 2 Results of the mechanical allodynia test using Von Frey filaments. Notes: Significant differences are seen between the groups, for both hind limbs (right hind limb: $F 3,28 . I=8.33[P=0.0004]$; left: $F 3,28 . I=22.68[P<0.000 I]$ ). No significant difference was seen between the baseline values of all the groups. Postsurgery, a significant decrease in the mechanical threshold in both hind limbs was noted for the CTL, AMI, CARBA, and GBP groups $(P<0.00 I)$. The decrease persisted even after the initiation of treatment (vehicle, AMI, or CARBA) from day 15 to 25 , suggesting no significant effect of these drugs on the bilateral mechanical allodynia induced by the collagenase intrathalamic injection when compared with day II ( $P=n s)$. However, after the initiation of treatment in the GBP group, a reversal of mechanical sensitivity was observed in both hind limbs at all the evaluation times $(P=n s$, when compared with the CTLs)

Abbreviations: AMI, amitriptyline; CARBA, carbamazepine; CTL, control; GBP, gabapentin; ns, nonsignificant.
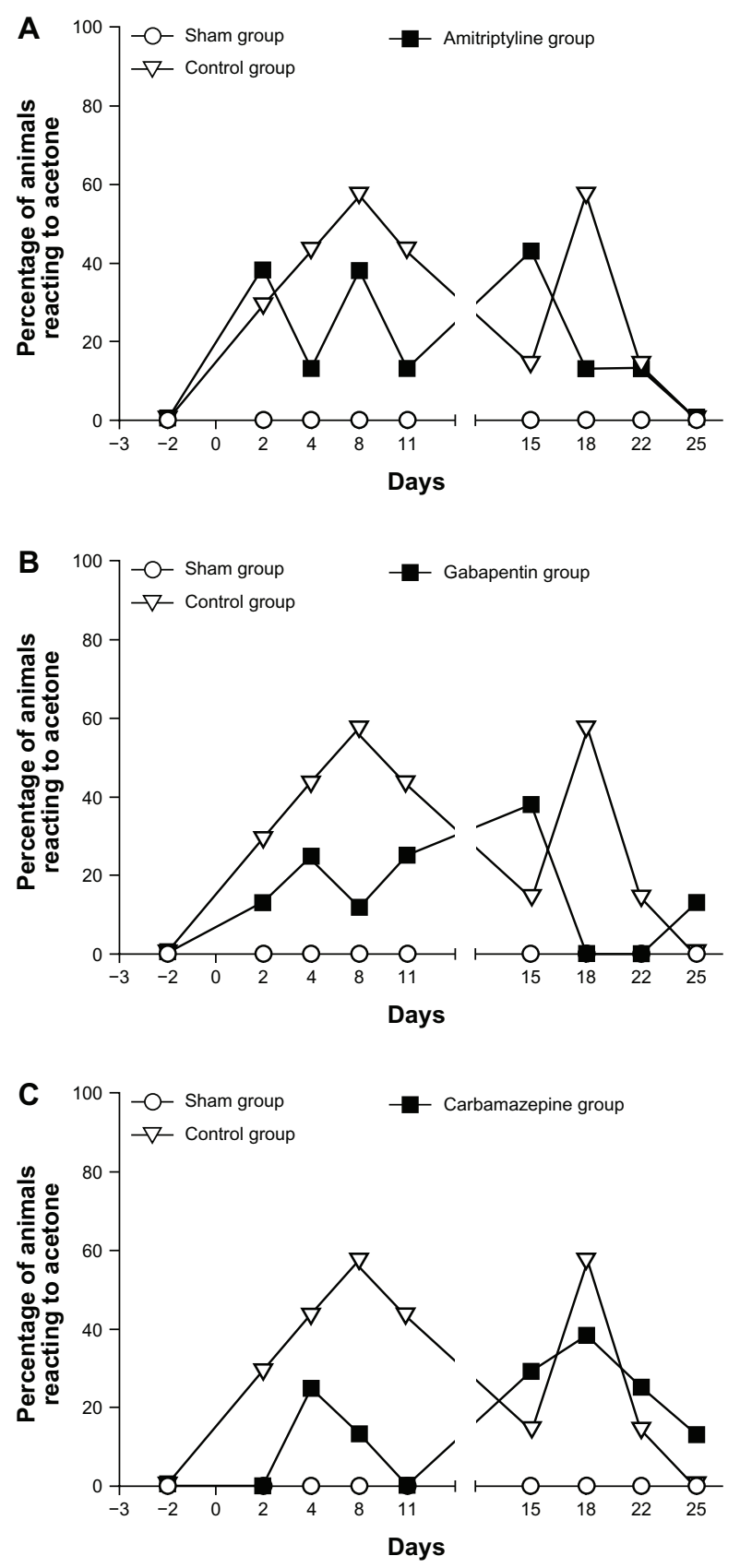

Figure 3 Evaluation of cold allodynia with the acetone test.

Notes: Results from the SHAM and CTL groups compared with the amitriptyline (A), gabapentin (B) or carbamazepine $(\mathbf{C})$ groups. The results are presented as the percentage of animals reactive to acetone. Although not statistically significant, the percentage of reactive animals in the CTL group appeared higher than that for the SHAM group. This increase in cold sensitivity returned to baseline at the end of the evaluation period (day 25). When comparing the different treatments (AMI, GBP, and CARBA) with the SHAM and CTL groups, the great variability within and between groups does not allow a clear conclusion.

Abbreviations: AMI, amitriptyline; CARBA, carbamazepine; CTL, control; GBP, gabapentin; SHAM, sham.

\section{Histopathological evaluations}

In the SHAM group, the microscopic evaluation of the brain slices was unremarkable. Conversely, in the collagenase group, small well circumscribed lesions were observed in the lateral thalamic nuclei (including the VPL) (Figure 5). 

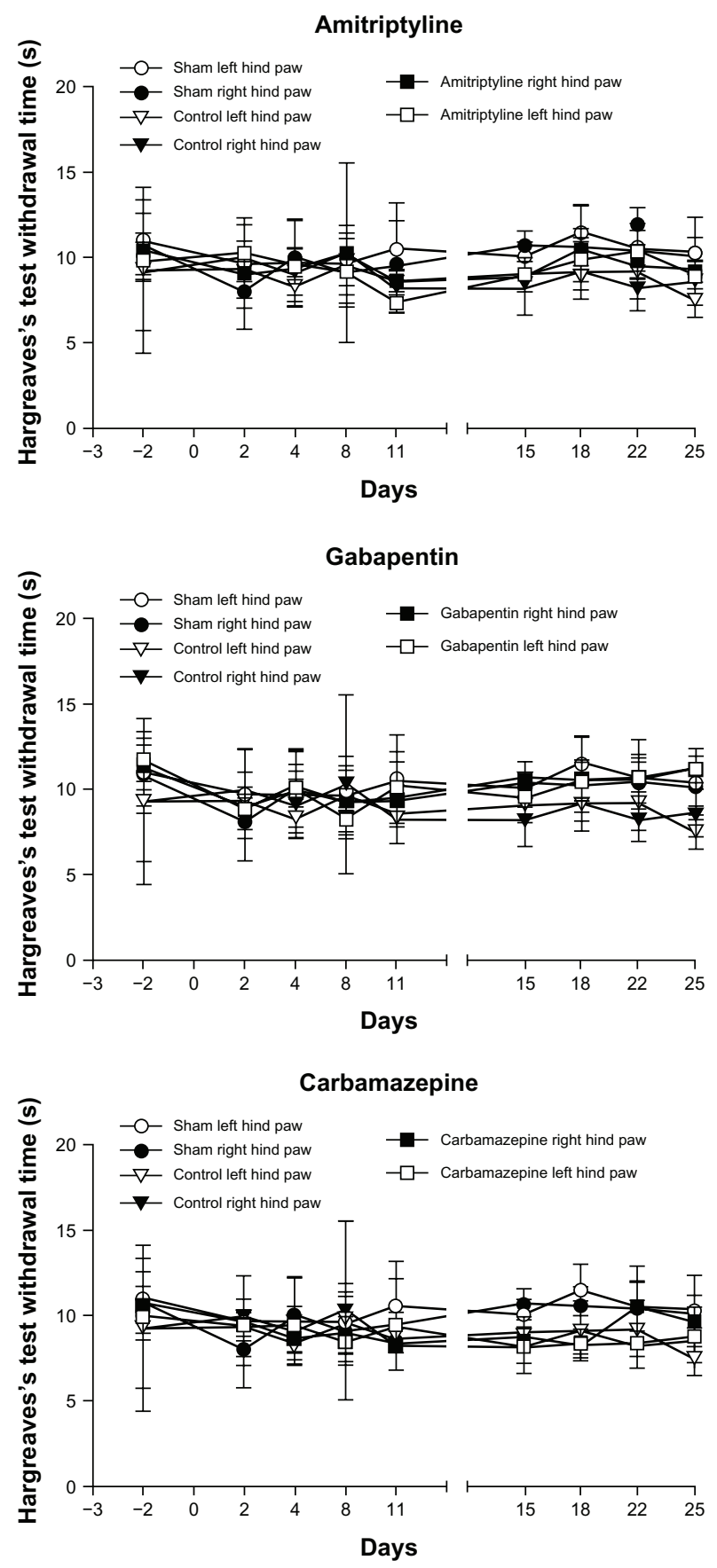

Figure 4 Thermal hyperalgesia using the Hargreaves test.

Notes: The results show no difference between the groups (right: F3, 28.2=1.36 [ns]; left: $F 3,28 . I=I .54$ [ns]). For all the groups, there was no significant difference in the thermal thresholds before and after the surgery, in both hind limbs $(F 8,|3|=|.4|$ $[P=n s], F 8,121=1.68[P=n s])$.

Abbreviation: ns, nonsignificant.

\section{Discussion}

A previously published, ${ }^{25}$ an animal model of central pain induced by an intrathalamic hemorrhage was used to assess AMI, GBP, and CARBA as potential therapeutic drugs. Following administration of a collagenase solution in the VPL thalamic nucleus, we observed a significant bilateral

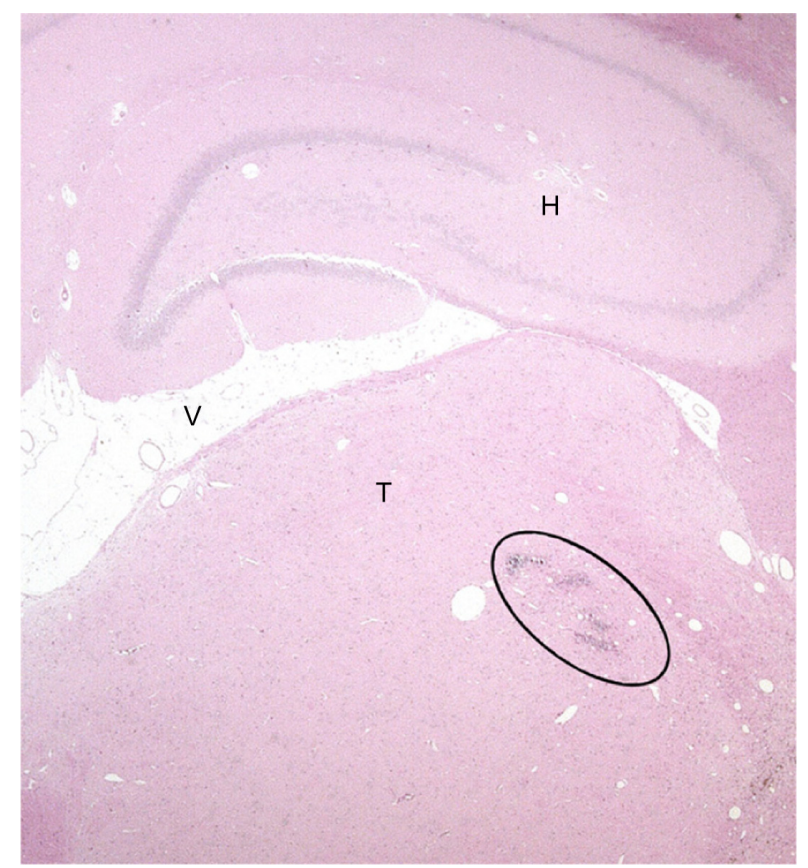

Figure 5 Photomicrograph of a transverse rat brain section $(4 \mu \mathrm{m})$ from the VPL nucleus of the thalamus.

Notes: Following a collagenase solution injection, a well-circumscribed small lesion is present in the thalamus (Hematoxylin and Eosin stain; $\times 12.5$ ).

Abbreviations: $\mathrm{H}$, hippocampus; $\mathrm{T}$, thalamus; $\mathrm{V}$, ventricle; VPL, ventroposterolateral.

mechanical allodynia up to 25 days after the intracerebral lesion, which developed as early as day 2 postsurgery. No sensitivity to heat developed in these animals, and a transient cold allodynia was observed only in some neuropathic animals. These results are similar to our previous findings ${ }^{25}$ and reflect the mechanical and cold allodynia that typically occur in humans following poststroke pain., ${ }^{910}$ At the dosages used, AMI and CARBA failed to show any significant effect on mechanical allodynia; however, GBP significantly alleviated mechanical sensitivity in both hind limbs. A putative effect of GBP on cold allodynia was only transient.

Mechanical allodynia is a clinical finding often reported in patients with CPSP., ${ }^{9,1132}$ Tactile hypoesthesia may also occur in the absence of mechanical allodynia. ${ }^{32}$ Our results show a persistent bilateral mechanical allodynia following the occurrence of a unilateral thalamic lesion, as was reported from previous findings..$^{25}$ Increased thermal thresholds, either to cold or hot temperatures, are frequently seen in CPSP patients. ${ }^{2}$ These changes can be characterized by either hyper- or hyposensitivity to cold, or warm temperature hyperalgesia. ${ }^{32}$ In the present study, we showed that the thermal heat sensitivity was unchanged in the animal with a thalamic lesion, which is concordant with our previous findings. ${ }^{25}$ In stroke patients, an increased sensitivity to cold and a decreased sensitivity to warmth occur frequently.,32 
Our results reflect the apparent low prevalence of hypersensitivity to noxious cold.

A possible mechanism of CPSP could be a loss of inhibition, plausibly following loss of gamma-aminobutyric acid (GABA)-Eric neurons or inhibition, particularly in the reticular nucleus surrounding the thalamus. ${ }^{33}$ It is also possible that allodynia and hyperalgesia in CPSP patients may result from glutamatergic neuronal hyperexcitability, which may be related to central sensitization. ${ }^{34,35}$ However, the precise pathophysiology of CPSP remains unclear. Although the mechanisms of CPSP are still poorly understood, the effect of GBP in reversing the mechanical allodynia associated with intrathalamic hemorrhage may allow us to gain some insight into the complexity of this condition. However, the mechanism of action of GBP is not fully defined. A synergy between increased GABA synthesis, non-N-methyl-Daspartate (NMDA) receptor antagonism, and binding to the $\alpha 2 \delta$ subunit of voltage-dependent calcium channels (CavCs) is suspected. ${ }^{18}$ The binding to the $\alpha 2 \delta$ subunit of $\mathrm{CavC}$ by GBP appears to be its most important mechanism of action to relieve neuropathic pain. ${ }^{18}$ It seems that this $\alpha 2 \delta$ subunit is involved in the inhibitory effects of GBP on stimulusevoked glutamate release. ${ }^{36}$ Repeated studies showed that GBP reduces glutamate release both in vitro and in vivo, in a model of peripheral neuropathic pain in rodents. ${ }^{36,37} \mathrm{GBP}-$ binding on $\alpha 2 \delta-1$ was shown to reduce calcium influx into the nerve terminals in response to action potential-mediated excitation, which would presumably diminish neurotransmitter release. ${ }^{38,39}$ Thus, GBP could influence central sensitization by decreasing NMDA receptor activity as its binding on the calcium channel would inhibit the release of excitatory neurotransmitters, such as glutamate. ${ }^{37}$ Importantly it is well recognized that CavCs modulate the central pain pathways by influencing fast synaptic transmission and neuronal excitability in the thalamus. ${ }^{40}$ In conclusion, GBP could modulate thalamic pain, both presynaptically and synaptically.

The efficacy of antidepressants in some CPSP patients suggests the involvement of noradrenergic, serotoninergic, and dopaminergic mechanisms. ${ }^{41}$ However, in our study, AMI failed to show any significant effect on mechanical allodynia. AMI has previously shown some degree of efficacy to relieve pain, at least partially, in CPSP patients, even in the absence of depression. ${ }^{11,42}$ The difference between our results and the response to AMI in human patients may be explained by some difference in methodology. CPSP patients achieved relief with AMI, and the difference in the rating of pain was 1 point on a pain scale when compared with placebo. ${ }^{42}$ Although this small difference might be appreciated by human patients, it may be too subtle to be reflected in an animal study. Furthermore, the dose we administered to the animals was not titrated to effect and was given only for a short period of time (10 days). In one clinical case, mechanical allodynia was reduced by about $50 \%$, but the AMI was titrated to effect and administered over a longer period of time. ${ }^{42}$ Important side effects occurred (sedation, dizziness, and difficulty concentrating), and the final recommendation was to take the drug only during particularly painful episodes. In our study, AMI was not given to effect, although the dose used in the rats $(10 \mathrm{mg} / \mathrm{kg})$ was much higher than the human dose (75 mg, or $1 \mathrm{mg} / \mathrm{kg}$ for a $70 \mathrm{~kg}$ person). We therefore expected a treatment effect with AMI, and an adjustment of the dose could be performed in future studies. We do not suggest that AMI is an unjustified choice for the treatment of central pain but rather, that a therapeutic dose without apparent side effects was ineffective to treat this condition.

CARBA did not show a significant effect in reducing the mechanical allodynia associated with an intrathalamic hematoma. These results are less surprising given the poor effect of this drug in human CPSP patients. ${ }^{11,42}$ These findings may suggest that sodium channel blocking by CARBA does not represent a major target for the treatment of CPSP.

In conclusion, we found that a collagenase-induced hemorrhage within the VPL thalamic nucleus of rats induced bilateral mechanical allodynia that was fully reversed by GBP. No thermal hyperalgesia to heat occurred; however, cold allodynia was noted in some animals. AMI and CARBA, at the concentration administered, failed to show any significant effect on the mechanical allodynia.

\section{Acknowledgments}

This study was supported by the Fond de Développement pour la Médecine des Animaux de Laboratoire. We wish to acknowledge Guy Beauchamp for statistical analyses as well as Jacinthe Cardin and Nancy Veilleux for their assistance in the brain preparation.

\section{Disclosure}

The authors report no conflicts of interest in this work.

\section{References}

1. Gilron I, Coderre TJ. Emerging drugs in neuropathic pain. Expert Opin Emerg Drugs. 2007;12(1):113-126.

2. Boivie J, Leijon G, Johansson I. Central post-stroke pain - a study of the mechanisms through analyses of the sensory abnormalities. Pain. 1989;37(2):173-185.

3. Fitzek S, Baumgärtner U, Fitzek C, et al. Mechanisms and predictors of chronic facial pain in lateral medullary infarction. Ann Neurol. 2001;49(4):493-500. 
4. Hansen AP, Marcussen NS, Klit H, Andersen G, Finnerup NB, Jensen TS. Pain following stroke: a prospective study. Eur J Pain. 2012;16(8):1128-1136.

5. Klit H, Finnerup NB, Andersen G, Jensen TS. Central poststroke pain: a population-based study. Pain. 2011;152(4):818-824.

6. Nasreddine ZS, Saver JL. Pain after thalamic stroke: right diencephalic predominance and clinical features in 180 patients. Neurology. 1997;48(5):1196-1199.

7. Bogousslavsky J, Regli F, Uske A. Thalamic infarcts: clinical syndromes, etiology, and prognosis. Neurology. 1988;38(6):837-848.

8. Krause T, Brunecker P, Pittl S, et al. Thalamic sensory strokes with and without pain: differences in lesion patterns in the ventral posterior thalamus. J Neurol Neurosurg Psychiatry. 2012;83(8):776-784.

9. Andersen G, Vestergaard K, Ingeman-Nielsen M, Jensen TS. Incidence of central post-stroke pain. Pain. 1995;61(2):187-193.

10. Bowsher D. Central pain: clinical and physiological characteristics. J Neurol Neurosurg Psychiatry. 1996;61(1):62-69.

11. Leijon G, Boivie J, Johansson I. Central post-stroke pain - neurological symptoms and pain characteristics. Pain. 1989;36(1):13-25.

12. Appelros P. Prevalence and predictors of pain and fatigue after stroke: a population-based study. Int J Rehabil Res. 2006;29(4):329-333.

13. Widar M, Ahlström G. Disability after a stroke and the influence of longterm pain on everyday life. Scand J Caring Sci. 2002;16(3):302-310.

14. Gordon A. Best practice guidelines for treatment of central pain after stroke. In: Henry JL, Panju A, Yashpal K, editors. Central Neuropathic Pain: Focus on Poststroke Pain. Seattle, WA: IASP Press; 2007: 267-273.

15. Kaur H, Hota D, Bhansali A, Dutta P, Bansal D, Chakrabarti A. A comparative evaluation of amitriptyline and duloxetine in painful diabetic neuropathy: a randomized, double-blind, cross-over clinical trial. Diabetes Care. 2011;34(4):818-822.

16. Leijon G, Boivie J. Central post-stroke pain - a controlled trial of amitriptyline and carbamazepine. Pain. 1989;36(1):27-36.

17. Mishra S, Bhatnagar S, Goyal GN, Rana SP, Upadhya SP. A comparative efficacy of amitriptyline, gabapentin, and pregabalin in neuropathic cancer pain: a prospective randomized double-blind placebo-controlled study. Am J Hosp Palliat Care. 2012;29(3):177-182.

18. Bennett MI, Simpson KH. Gabapentin in the treatment of neuropathic pain. Palliat Med. 2004;18(1):5-11.

19. Attal N, Brasseur L, Parker F, Chauvin M, Bouhassira D. Effects of gabapentin on the different components of peripheral and central neuropathic pain syndromes: a pilot study. Eur Neurol. 1998;40(4):191-200.

20. Chapman V, Suzuki R, Chamarette HL, Rygh LJ, Dickenson AH. Effects of systemic carbamazepine and gabapentin on spinal neuronal responses in spinal nerve ligated rats. Pain. 1998;75(2-3):261-272.

21. Jeanmonod D, Magnin M, Morel A. Low-threshold calcium spike bursts in the human thalamus. Common physiopathology for sensory, motor and limbic positive symptoms. Brain. 1996;119(Pt 2):363-375.

22. Lenz FA, Tasker RR, Dostrovsky JO, et al. Abnormal single-unit activity recorded in the somatosensory thalamus of a quadriplegic patient with central pain. Pain. 1987;31(2):225-236.

23. Wasserman JK, Koeberle PD. Development and characterization of a hemorrhagic rat model of central post-stroke pain. Neuroscience. 2009;161(1):173-183.

24. Rosenberg GA, Mun-Bryce S, Wesley M, Kornfeld M. Collagenaseinduced intracerebral hemorrhage in rats. Stroke. 1990;21(5):801-807.

Journal of Pain Research

\section{Publish your work in this journal}

The Journal of Pain Research is an international, peer-reviewed, open access, online journal that welcomes laboratory and clinical findings in the fields of pain research and the prevention and management of pain. Original research, reviews, symposium reports, hypothesis formation and commentaries are all considered for publication.
25. Castel A, Hélie P, Beaudry F, Vachon P. Bilateral central pain sensitization in rats following a unilateral thalamic lesion may be treated with high doses of ketamine. BMC Vet Res. 2013;9:59.

26. Paxinos G. Watson C. The Rat Brain: in Stereotaxic Coordinates. San Diego, CA: Academic Press Inc; 1998

27. Chaplan SR, Bach FW, Pogrel JW, Chung JM, Yaksh TL. Quantitative assessment of tactile allodynia in the rat paw. $J$ Neurosci Methods. 1994;53(1):55-63.

28. Choi Y, Yoon YW, Na HS, Kim SH, Chung JM. Behavioral signs of ongoing pain and cold allodynia in a rat model of neuropathic pain. Pain. 1994;59(3):369-376.

29. Hargreaves K, Dubner R, Brown F, Flores C, Joris J. A new and sensitive method for measuring thermal nociception in cutaneous hyperalgesia. Pain. 1988;32(1):77-88.

30. Field MJ, McCleary S, Hughes J, Singh L. Gabapentin and pregabalin, but not morphine and amitriptyline, block both static and dynamic components of mechanical allodynia induced by streptozocin in the rat. Pain. 1999;80(1-2):391-398.

31. Chogtu B, Bairy KL, Smitha D, Dhar S, Himabindu P. Comparison of the efficacy of carbamazepine, gabapentin and lamotrigine for neuropathic pain in rats. Indian J Pharmacol. 2011;43(5):596-598.

32. Greenspan JD, Ohara S, Sarlani E, Lenz FA. Allodynia in patients with post-stroke central pain (CPSP) studied by statistical quantitative sensory testing within individuals. Pain. 2004;109(3):357-366.

33. Liao YF, Tsai ML, Chen CC, Yen CT. Involvement of the Cav3.2 T-type calcium channel in thalamic neuron discharge patterns. $\mathrm{Mol}$ Pain. 2011;7:43.

34. Sessle BJ. Mechanisms of pain. In: Henry JL, Panju A, Yashpal K, editors. Central Neuropathic Pain: Focus on Poststroke Pain. Seattle, WA: IASP Press; 2007:67-79.

35. Vestergaard K, Nielsen J, Andersen G, Ingeman-Nielsen M, ArendtNielsen L, Jensen TS. Sensory abnormalities in consecutive, unselected patients with central post-stroke pain. Pain. 1995;61(2):177-186.

36. Quintero JE, Dooley DJ, Pomerleau F, Huettl P, Gerhardt GA. Amperometric measurement of glutamate release modulation by gabapentin and pregabalin in rat neocortical slices: role of voltage-sensitive Ca2+ $\alpha 2 \delta$-1 subunit. J Pharmacol Exp Ther. 2011;338(1):240-245.

37. Coderre TJ, Kumar N, Lefebvre CD, Yu JS. Evidence that gabapentin reduces neuropathic pain by inhibiting the spinal release of glutamate. J Neurochem. 2005;94(4):1131-1139.

38. Fink K, Dooley DJ, Meder WP, et al. Inhibition of neuronal $\mathrm{Ca}(2+)$ influx by gabapentin and pregabalin in the human neocortex. Neuropharmacology. 2002;42(2):229-236.

39. Tuchman M, Barrett JA, Donevan S, Hedberg TG, Taylor CP. Central sensitization and $\mathrm{Ca}(\mathrm{V}) \alpha_{2} \delta$ ligands in chronic pain syndromes: pathologic processes and pharmacologic effect. J Pain. 2010;11(12): 1241-1249.

40. Todorovic SM, Jevtovic-Todorovic V. T-type voltage-gated calcium channels as targets for the development of novel pain therapies. Br J Pharmacol. 2011;163(3):484-495.

41. Henry JL. Central poststroke pain: an animal model. In: Henry JL, Panju A, Yashpal K, editors. Central Neuropathic Pain: Focus on Poststroke Pain. Seattle, WA: IASP Press; 2007:171-180.

42. Hansson P. Post-stroke pain case study: clinical characteristics, therapeutic options and long-term follow-up. Eur J Neurol. 2004; 11 Suppl 1:22-30

The manuscript management system is completely online and includes a very quick and fair peer-review system, which is all easy to use. Visit http://www.dovepress.com/testimonials.php to read real quotes from published authors. 